Fecha de recepción: mayo 2021 Fecha de aceptación: junio 2021 Versión final: julio 2021

\section{Irse o volver: entre el drama y la comedia. Exiliados económicos en el cine argentino (2001 - 2011) \\ Verónica Chelotti ${ }^{(1)}$}

Resumen: El objetivo de este artículo es analizar la representación de los exiliados económicos argentinos en el cine de ficción producido en Argentina entre los años 2001 y 2011. Nos centraremos en el análisis de las estrategias y los recursos que utilizan los filmes para construir los personajes, teniendo como hipótesis que dichas construcciones refuerzan los prejuicios que provienen del mundo real. En segundo lugar proponemos indagar sobre el contexto histórico representado: la crisis económica, política y social argentina del 2001. El corpus fílmico está compuesto por las películas: Lugares comunes (Aristarain, 2002) y Güelcom (Blanco, 2011), ficciones producidas en distintos momentos históricos relevantes para abordar la emigración a España, y el retorno hacia Argentina. El abordaje propuesto entiende al cine como artefacto de memoria, que permite mirar el pasado que se elige recordar, a la vez que da cuenta de lo que se quiere olvidar.

Palabras clave: exilio económico - emigrante argentino - identidad - crisis del 2001.

[Resúmenes en inglés y portugués en la página 116]

(1) Licenciada en Comunicación Social (Universidad Nacional de Quilmes). Se especializó en Comunicación y Diversidad Cultural (Universidad Autónoma de Barcelona). Trabaja como jefa de Producción en la Unidad Audiovisual de la Universidad Nacional Arturo Jauretche. Es docente del Programa UPAMI (la Universidad de los Adultos Mayores). Integra el equipo de investigación del Centro Historia Cultura y Memoria de la UNQ.

\title{
Introducción
}

El tema de este trabajo es la representación de los exiliados económicos argentinos en el cine. El corpus está compuesto por dos filmes de ficción argentinos producidos entre los años 2001 y 2011. Nos centraremos en analizar, por un lado, las estrategias y los recursos que utilizaron estos filmes para construir la identidad de los emigrantes o exiliados económicos y, por otro, su contexto histórico: la crisis económica que provocó la emigración más importante de la historia argentina. 
La elección del cine como fuente descansa en parte en la lectura de Robert Rosenstone (2014), quien sostiene que los filmes producen versiones de la historia que invitan a reflexionar sobre cómo se reconstituye el pasado. El autor afirma que una película de tema histórico siempre es algo más que un conjunto de hechos, es también un drama, una representación, una obra que pone en escena y construye un pasado en imágenes y sonidos. Siguiendo su planteo, sostenemos que los discursos en torno a la figura del exiliado han cambiado según el momento histórico en el que fueron enunciados.

El cine argentino de las últimas décadas, si bien ha demostrado un especial interés en la última dictadura cívico-militar, y en los exiliados políticos, tardó en poner el foco en el movimiento migratorio que provocó la crisis económica de finales de la década de los ochenta, así como sobre el éxodo de argentinos post 2001.

En este sentido, el aporte que ha hecho el cine a la construcción del exiliado político fue analizado en numerosos estudios académicos de distintas disciplinas y universidades argentinas, enriqueciendo ampliamente la discusión y el análisis crítico sobre la representación de ese actor social.

Sin embargo, sobre la temática elegida del exiliado económico es menor la producción, dicho sujeto, no cuenta con el mismo protagonismo que su par político ni en las pantallas ni en la producción academia.

Cabe señalar que durante los primeros años de la década del 2000 se produjeron algunos filmes de ficción argentinos que tuvieron como protagonistas personajes que deseaban o concretaban el proyecto migratorio ${ }^{1}$, sin embargo, las películas que componen el corpus de este trabajo: Lugares comunes (Aristarain, 2002) y Güelcom (Blanco, 2011) son las únicas que permiten abarcar las distintas etapas del proceso migratorio: emigración, inmigración y retorno hacia y desde España.

En este sentido, los filmes pueden pensarse como artefactos de memoria, al respecto Tzvetan Todorov (1995) define a la memoria como la interacción entre lo que se recuerda y lo que se olvida. La memoria no es propiedad de la mente, sino una elaboración social que se desarrolla de acuerdo con marcos sociales: el recuerdo se hace desde un lugar, desde una historia que es la confluencia de la experiencia del sujeto con normas, valores culturales, marcos institucionales que lo habitan y le permiten pensar el mundo, reconocerlo y recordarlo. Entonces, la memoria colectiva -en tanto memoria situada- es imprescindible en la formación de la identidad de un grupo social.

Sus miembros reconstruyen el pasado, lo seleccionan e interpretan a través de la interacción que les permiten sus marcos de referencia comunes. Y el cine -en cuanto dispositivo técnico, estético y cultural- es un legitimado constructor y reproductor de memorias e imaginarios sociales, de miradas situadas en una época y en un espacio, y sus narraciones influyen, intervienen en las formas en las que estructuramos al mundo.

En ese mismo orden de ideas nos preguntamos ¿qué hay de olvido y de recuerdo en torno al exilio económico de miles de personas provocado por la crisis del neoliberalismo en la Argentina de principios del siglo xxi? y ¿cómo ha colaborado el cine en la construcción identitaria de ese nuevo actor social que a priori encontramos muy poco presente? Consideramos que los filmes son fuentes valiosas para analizar el fenómeno sociohistórico que nos alienta a escribir este trabajo, que está centrado en pensar el exilio económico 
de argentinos hacia España después del año 2001. En esta dirección, hacemos propias las palabras de (Ferro, 1991) cuando enuncia que "lo que interesa no es el pasado, sino el vínculo, la relación profunda entre pasado y presente” (p. 3).

\section{Los exilios}

En el plano teórico suele asociarse la salida del país por la fuerza con la categoría exilio y la partida por cuestiones económicas con la emigración; pero esa oposición no es tan categórica en la vida de las personas. Giorgio Agamben (1996) define el exilio como "la figura de la vida en su inmediata y originaria relación con el poder soberano" (p. 41). En tanto esta definición considera que es el Estado el que tiene la potestad de expulsar a alguien, de ponerlo en estado de excepción, de negarle el derecho a la ciudadanía, consideramos que las políticas que llevaron a cabo los gobiernos argentinos que produjeron la crisis económica del 2001, expulsaron a miles de argentinos y argentinas de la misma manera que lo hicieron en los dos momentos históricos previos en los que tuvo lugar este fenómeno de naturaleza política y demográfica: la dictadura cívico-militar que derrocó el tercer gobierno peronista en 1976 y la hiperinflación de 1989. El significante exiliado, tan cercano a nuestra literatura académica y a nuestra filmografía, no distingue salida o llegada, es un no lugar. ${ }^{2}$ En cambio el concepto emigrado o inmigrante refiere indefectiblemente a dos lugares: el de procedencia y el de destino.

Por su parte, si el exilio se asocia con imposición y la emigración con acto voluntario, Fernando Osvaldo Esteban (2003) matiza la diferencia y establece grados de voluntariedad del traslado, identificando dos tipos de movimientos migratorios: los espontáneos que son los que voluntariamente emigran y los forzados que son los que no eligen dejar su lugar de residencia y en algunos casos tampoco eligen el lugar donde emigrar. De acuerdo con esta definición, cabe la pregunta acerca del grado de elección que tienen los emigrantes económicos, si se van de sus lugares motivados por el desfase entre sus expectativas y la posibilidad de satisfacerlas. Con este argumento consideramos pertinente utilizar el término exilio económico para referir a los desplazamientos de cientos de miles de argentinos durante las crisis del 89 y la de 2001, cuya salida implicó forzosamente una ruptura con la propia identidad individual y para los cuales el regreso no era una opción voluntaria.

Respecto a los argentinos que emigraron a España por razones económicas a principio de los años 2000 es necesario señalar que no poseían el mismo estatus del exiliado político que había emigrado para salvar su vida, tampoco compartían características con la llamada fuga de cerebros de los sesenta. El exiliado económico pasó a formar parte del total de inmigrantes a secas que engrosaban el número de sudamericanos en la península ibérica. En relación con el proceso histórico es necesario señalar que España experimentó entre 1997 y 2005 un exponencial aumento de inmigrantes que pasó de 637.000 a 4,1 millones. El mayor flujo de argentinos llegó entre los años 2000 y 2005. En 2001 había 93.872 argentinos, número que se elevó en 2008 a 295.401 empadronados. A pesar de las políticas de arraigo y la crisis europea, en 2013 se registraban 270.419 argentinos en suelo español (Instituto Nacional de Estadísticas de España). 
La escasa representación existente en el cine argentino de los emigrantes económicos y la vacancia de análisis cobran mayor relevancia ante las cifras del referente real expuesto. Para el análisis se seleccionaron películas de ficción producidas en Argentina durante la primera década del siglo xxI que narrasen la crisis argentina y la emigración: Lugares comunes (Adolfo Aristarain, 2002) y Güelcom (Yago Blanco, 2011) fueron producidos en dos momentos históricos diferenciados relevantes para abordar la emigración a España y el retorno hacia Argentina entre 2002 y 2011. Por otra parte las películas abordan el tema desde dos géneros diferentes: la comedia romántica y el drama, sus directores cuentan con trayectorias muy diversas: mientras Aristarain tiene una vasta producción, Blanco solo cuenta con dos largos estrenados. Finalmente, aunque la crítica calificó a una y descalificó a la otra, ambas gozaron de muy buena recepción en los espectadores.

Una de las hipótesis que guía el trabajo es que los procesos de semiosis que se originan a través de estos filmes construyen y cristalizan la figura de un emigrante estereotipado: blanco, de clase media, profesional, urbano e individualista, que emigra a España porque las condiciones sociopolíticas de su país de origen no le permiten su realización personal. Otra de las ideas que nos guiaron está referida a la estrecha relación que existe entre las versiones de la inmigración que plantean los filmes y el contexto histórico de producción. Por último, intuimos que la escasez de filmes sobre la temática refiere al trauma de la emigración provocada por una crisis económica, política y social sin precedentes, es por ello que creemos relevante el ejercicio de memoria, así como la reflexión sobre el presente. ${ }^{3}$

\section{Análisis de los filmes: Lugares comunes y Güelcom}

Lugares comunes es un drama guionado y dirigido por Adolfo Aristarain que se estrenó en Argentina en el año 2002. Se basa en una novela llamada El renacimiento de Lorenzo Aristarain, geólogo y primo del director. El segundo filme es Güelcom, ópera prima del director Yago Blanco, estrenada en 2011. Los filmes pueden ser pensados, en términos de Rosenstone, como drama (1997) porque los procesos sociales están encarnados en individuos, suponen cierta idea del progreso de la historia y se estructuran a partir de narraciones clásicas. Estas aluden, según David Bordwell (1996), a los sistemas narrativos temporales y espaciales estandarizados, cuyas normas estilísticas se estructuran a partir del montaje de continuidad, la invisibilidad de la narración, la reducción de la ambigüedad y la pretensión de universalidad de las historias que cuentan. Se trata de un cine narrativo que persigue la idea de continuidad, en el que los personajes presentan rasgos definidos y estables en todo el filme y la historia se presenta como equilibrio, ruptura de este y, finalmente, restablecimiento.

En estos filmes, el punto de vista es el del protagonista. La historia la narran Fernando en Lugares comunes y Leo en Güelcom, quienes llevan la acción y están presentes en la mayoría de las escenas, marcan tanto el eje del relato como su línea dramática. 


\section{Los filmes}

Lugares comunes relata la historia de una pareja de adultos mayores compuesta por Fernando Robles (Federico Luppi) y Lili (Mercedes Sampietro ${ }^{4}$ ) que debe enfrentar la crisis económica del 2001. A él, profesor de literatura, lo jubilan antes de tiempo. Ella es asistente social. Ambos tienen un hijo en España, Pedro (Carlos Santamaría), quien les paga un viaje para que lo visiten y, efectivamente, sus padres pasan unos días allí aunque rechazan tanto su ayuda económica como su invitación a quedarse en Madrid. Al regresar a la Argentina, se ven obligados a vender su casa, heredada de los padres de ella, y emigrar a la provincia de Córdoba, donde emprenden un negocio, que el protagonista no llega a ver porque muere.

Güelcom es una historia de amor entre Leo (Mariano Martínez) y Ana (Eugenia Tobal). Esta historia termina cuando Ana decide emigrar hacia España y Leo decide quedarse en Buenos Aires. En este filme, la elaboración de un decálogo con las frases más usadas por los argentinos que se van del país ${ }^{5}$, sirve tanto para hilar la narración como para observar con humor e ironía las distintas conductas que toman los personajes para justificar sus acciones: la emigración y el retorno. El casamiento de unos amigos, también emigrados, los reencuentra después de cuatro años. Leo inicia un plan para reconquistar a Ana y, al final, se burla de sus propios postulados, ya que él también decide irse.

\section{Los que se van y los que se quedan}

El Lugares comunes Fernando Robles, el protagonista del filme, elige no emigrar en el 2001, a pesar de la dura situación económica que debe enfrentar en los últimos años de vida. La narración da cuenta de que ha experimentado el exilio en la década de los setenta. Liliana Rovira, su esposa, es asistente social en un barrio marginal de Buenos Aires, en un contexto de hambre y recortes estatales. Este personaje condensa las trayectorias de exilios y migraciones múltiples: el primero a causa de la dictadura franquista hacia Francia; el segundo, ya con 20 años ella, hacia la Argentina; y el tercero -que es exilio y retorno- hacia su país de origen a causa de la dictadura cívico-militar de 1976.

Pedro Robles, el hijo de ambos, es un exiliado económico. Emigró de la Argentina poco antes del estallido social del 2001 para radicarse en la España pujante. Posee la documentación que acredita la nacionalidad española heredada de su madre. Vive en una de las urbanizaciones de clase media acomodada en las afueras de Madrid, producto de la desaforada construcción de viviendas que experimentaba por entonces ese país. ${ }^{6}$ Ha cambiado su vocación de escritor por la informática. Su compañera de vida, también argentina, no se siente inmigrante; para ella ese lugar es para los otros del mundo que han invadido España, como los moros o ecuatorianos. Conocemos sobre la emigración de Pedro a través de los ojos de sus padres, que lo cuestionan porque no comparten su decisión. 
Por su parte, Güelcom gira en torno a Leo, un joven psicólogo que no quiso irse del país y por esa decisión perdió a Ana, el amor de su vida. Él lo resume en esta frase: "Ella me dejó porque quería irse a vivir a otro lado. Y yo la dejé porque quería quedarme". Al final del filme emigra para vivir con ella en Barcelona.

Ana emigró a España en años posteriores al estallido. Se fue porque quería probar suerte. Trabajaba como cocinera y en Argentina sentía que no podía realizarse profesionalmente. Tampoco lo logró en Barcelona, donde tuvo que conformarse con un trabajo de camarera. El retorno a su lugar de origen pone en duda su decisión, y el verbo volver se confunde de destino. Pero el final revela que la vuelta será a España.

El grupo de amigos de la pareja que viven en la ciudad de Buenos Aires: Javier (Peto Menahem), su compañera Andy (Maju Lozano) y Sol, la amiga soltera (Eugenia Guerty), esperan a los que viven en Ibiza: Martín (Gonzalo Suárez) y Julieta (Ana Yovin) también emigrados pos 2001 como Ana, y quienes se fueron sin un plan, sin saber por qué, ni adónde iban. El casamiento de Martín y Julieta en Buenos Aires es el reencuentro, pero también una nueva despedida. La pareja de emigrados regresa, como Ana, a España.

\section{Representaciones identitarias}

En este texto se entienden las identidades en tanto representaciones que se construyen dentro del discurso y a partir de la diferencia con el otro. No responden al quiénes somos o de dónde venimos, sino cómo nos han representado o cómo podríamos representarnos (Hall, 2003). Se indagara en los textos fílmicos la significación de España y las marcas que remiten a la españolidad.

En los dos filmes analizados España aparece nombrada como el lugar de la salvación, al menos de la salvación económica. Esto se convierte en tópico y lugar común que se reitera, con diferentes tonos, en ambas películas. Esa banalidad que, según Gourmont (1900) (citado en Amossy y Herschberg, 2001), se define por ser tan universalmente aceptada que toma el nombre de verdad y hasta se convierte en el nombre del filme. Lugares comunes también refiere a las preguntas filosóficas que Fernando utiliza para reflexionar junto sus estudiantes.?

Por su parte, para nombrar su filme, Blanco recurre a la ironía, a los clichés, en tanto "categorías descriptivas simplificadas basadas en creencias y en imágenes reductoras, por medio de las cuales calificamos a las demás personas o a otros grupos sociales, sujetos a prejuicios" (Fischer, 1996, p. 133). Esto se evidencia en el título elegido para la película, Güelcom, y luego en las placas gráficas que se exponen en el filme con la palabra bienvenido en diferentes idiomas -como se utiliza en los aeropuertos- en cada uno de los puntos de giros de la estructura dramática. El director elige nombrar al filme con un bienvenido en inglés, pero con un error gramatical que lo castellaniza, vinculándolo de este modo a la práctica obligatoria en España de doblar todas las películas habladas en otro idioma.

En segundo lugar, el filme juega con el doble sentido del significante Güelcom, que no siempre significa bienvenido. El enrarecimiento del nombre da cuenta de la identidad 
difusa que los liga a dos países y a ninguno. El realizador expresa con esa ironía que los exiliados económicos pos 2001 no son bienvenidos en Argentina, ni en España.

Otra de las estrategias que utiliza el filme es el catálogo de las frases más usadas por los argentinos que deciden irse del país, que según el protagonista "son falsas, pero los argentinos las repiten como verdaderas", con esto explicita el tema de los clichés.

Respecto al filme de Aristarain, España es un lugar común para los tres personajes y para los enunciatarios que construyen el filme.

La pareja protagonista de Lugares comunes vive un doble reencuentro en Madrid: con el hijo emigrado, que ha renunciado a ser su discípulo y a seguir peleándola en la Argentina, y con la ciudad que los acogió durante el exilio. Fernando la describe así: "Madrid estaba realmente hermosa, brillante, envidiable ejemplo de la prosperidad del primer mundo del que nos empujaban cada vez más lejos". Lo dice al comparar esa ciudad europea con su Buenos Aires en crisis económica, política y social en la que acababan de jubilarlo por falta de fondos para la educación pública.

Fernando: - Aunque solo habíamos vivido seis años en Madrid, después de que los milicos nos invitaran a exiliarnos si queríamos seguir vivos, sentimos que no éramos turistas, que la ciudad seguía siendo nuestra (...).

Las palabras de Fernando no solo halagan al espectador español, ávido de ser identificado con el primer mundo, sino que apelan a la identificación de los argentinos con ese territorio que sienten propio, del que pueden salir y entrar cuando quieran, que no ha sido hostil, sino gratificante, afín a su cultura. Madrid es recordada con nostalgia, a pesar del exilio político.

Esa familiaridad también la expresa la nuera de los protagonistas. La cámara recorre lentamente un bar madrileño, no se detiene ni en los extras ni en los jamones colgados sobre la barra. Panea por los extras que son físicamente parecidos a los protagonistas argentinos y se detiene en ellos, que beben en una barra. El sonido ambiente de copas y charlas disminuye para que escuchemos el diálogo entre la nuera y la suegra. Fabiana le cuenta con énfasis a su suegra sobre las supuestas diferencias culturales que hay entre ellos y los otros inmigrantes, como moros y ecuatorianos que han llegado a Madrid, negando cualquier intención racista: "no tengo nada en contra, pero...", "también hay algunos buenos, pero...", "nosotros trabajamos mucho y ellos vienen a no hacer nada". Tales estrategias semánticas y retóricas -uso de pronombres personales y demostrativos- se aplican para exponer argumentos y contar anécdotas concretas basadas en la experiencia personal y que, por lo tanto, son prueba fiable de las conclusiones negativas. Ella y su marido argentinos nacionalizados españoles, como su suegra española de origen, pertenecen, tienen derecho natural sobre el territorio España, los otros, la india ecuatoriana o la africana que cuidan niños, son invasores de esa tierra.

Pedro le dice a su padre que España es "otro mundo, es un país en serio" (...) "tengo una casa, dos coches, los chicos van a poder estudiar lo que quieran y donde quieran, no puedo pedir más". Esa frase desencadena el diálogo que, además de ser el clímax del filme, nos permite analizar ideas acerca de la españolidad. Es una discusión entre dos generaciones: 
uno decidió apostar por su país a pesar de perder todas las batallas, el otro eligió emigrar para tener, en lugar de ser:

Fernando: - Te guste o no sos un exiliado, un sudaca que le está quitando el trabajo a un gallego desocupado, cuando tu querida empresa tenga que achicarse porque llegó la recesión, al primero que le van a dar una patada en el culo [sic] es a vos, ¿tenés alguna duda? Pedro: - Yo no soy ningún sudaca, soy español, tengo nacionalidad española.

Fernando:-Sabes por dónde me paso yo eso de la patria, la bandera y la escarapela. Vos te vendiste Pedro, vos renegaste de tu país por guita, porque te conviene, vos no sos español, sos otra cosa. No te voy a decir lo que sos, lo sabes más que nadie.

El diálogo entre padre e hijo condensa la contradicción y las tensiones identitarias que experimentaron muchos argentinos al llegar a España. El apellido europeo o la ciudadanía no eran suficientes para ser español. Pero unos (Fernando) como otros (Pedro) se esforzaron para ser reconocidos como iguales y exigieron a la sociedad de acogida que los reconociera así. Acreditaban una deuda histórica, por haberlos recibido primero.

En este filme la construcción de la españolidad se explicita por oposición, existe porque excluye a los otros, a los no españoles, y en ese universo están incluidos los argentinos, más allá de sus antepasados, más allá del pasaporte (Augé, 2000).

En Güelcom Leo tiene la misma intención que Fernando en Lugares Comunes, de desmitificar ese lugar común enunciado por los tres personajes emigrados del filme, de que afuera se tendrán mejores oportunidades. Dos de las frases más usadas por los argentinos que se van del país que Leo considera falsas, aunque se repitan como verdaderas son: "me fui porque acá no podía desarrollarme en lo mío" y "allá hay mejores horizontes profesionales". Ambas sentencias remiten a España como un lugar-paraíso. La cámara acompaña la idea: lo que vemos de España son playas hermosas en las que los protagonistas son felices. No obstante, la frase del catálogo: "Allá hay mejores horizontes profesionales" se desmiente en más de una escena:

Martín: - Allá si querés hacer tu historia nadie te jode, no importa que querés hacer, no está esa presión que está acá, si querés ser basurero nadie te va a mirar mal por eso, es un trabajador como cualquier otro, te pagan y te respetan.

Javier: $-_{¿}$ Cuánto gana un basurero?

Martín: -800, 1000 euros.

Sol: - Entonces te conviene irte a España que quedarte acá.

Javier: -No entendés nada, nena, allá es diferente, no es como ser basurero acá.

Sol: - Vos no entendés nada, nene, que ¿vos te harías basurero acá?

Las expectativas profesionales de Ana no se cumplieron. Martín y Julieta vuelven a España para vivir bronceados todo el año. Los que se fueron han sacrificado sus vocaciones en pos de una mejor calidad de vida. El narrador protagonista que se burla de todos estos postulados, al final del filme también emigra a probar suerte. España es la tierra elegida para ser felices. 
En el sistema de personajes de Güelcom la españolidad aparece con relación a Oriol, el novio español de Ana, que se presenta antipático, desagradable y motivo de discordia entre los amigos. Él es el único personaje español "legítimo". Los otros no lo son ni lo serán, a pesar de que los emigrados digan que viven muy bien en España y utilicen modismos del lenguaje que solo se usan allí, como los chistes fáciles sobre los significantes coger y coñazo, entre otros. A pesar que el tema de la migración en esta película, es un pretexto, un telón de fondo para la comedia romántica, establece una crítica clara frente a la búsqueda de ese paraíso europeo que se plantea como un espejismo.

Es posible sostener que en ambas películas converge una idea que impregnaba el inconsciente colectivo durante los años de la crisis argentina: España como el lugar de la salvación a los problemas no solo económicos, sino también de realización personal; de este modo, se plantea que el futuro no es tanto una variable de tiempo sino de espacio. El futuro está en Europa.

Acerca de las nociones de argentinidad es posible sostener que en el filme de Aristarain, Argentina es el lugar de la expulsión, de la imposibilidad para concretar sueños, de la incertidumbre constante, del dolor.

El diálogo entre padre e hijo en el aeropuerto entrama el exilio político y el económico dan cuenta de la causa de ambas partidas, siempre involuntarias. Los que creyeron en la revolución retornan, a pesar de su hostilidad; los más jóvenes permanecen en Europa.

Pedro: - El país está muy mal pero eso es una excusa. Yo me siento un traidor, me fui, me escapé.

Fernando: - Vos no te fuiste, te echaron, como me echaron a mí y a todos los que se van. Tu país se murió, no existe, así que dejate de joder con la nostalgia y trata de ver las cosas como son, no te dejan vivir, tenés que sobrevivir, no te sientas culpable de nada, cuando se trata de seguir vivo no hay reglas Pedro, las reglas las borraron, vale todo, podes venderte pero no entregarte, un día vas a salir de todo esto y vas a ser vos mismo. No te pierdas.

En otra escena, la cámara muestra el palacio de Justicia de Buenos Aires, Tribunales, mientras escuchamos a Fernando resignado: "Hay un país que nos destruye, un mundo que nos expulsa, un asesino difuso que nos mata día a día sin que nos demos cuenta" (...) "Me preguntaba como otras veces ¿qué carajos estamos haciendo aquí, qué esperábamos, por qué no nos íbamos de una vez por todas? Como otras veces no encontré la respuesta y nos seguimos quedando".

"El Asesino difuso" es su terruño, su "lugar en el mundo" a pesar de que lo ha traicionado al punto de provocar el exilio económico de su único hijo.

Por su parte, en Güelcom, cuando Ana regresa a Buenos Aires, la cámara lenta panea para mostrarla luminosa, espléndida, desde los pies hasta la cabeza. Dentro del aeropuerto respira aire fresco mientras su pelo se mueve con el viento. Pero esa plenitud se interrumpe al atravesar la puerta de vidrio que la ubica en Buenos Aires. Tiene la impresión de que le han robado el bolso. Ahí aparece la primera de las frases del decálogo: "Este país es una mierda” [sic]. Pero el bolso estaba en el piso. Así, en este caso el taxista, se burla y desmiente el tópico. 
$\mathrm{Al}$ reencontrarse con sus amigas, Ana les dice: “Tenía muchas ganas de venir" en un abrazo fraternal. Ese afecto está ausente en su vida española. Esto lo vemos también en la pareja que vuelve para celebrar su fiesta de casamiento: "Este es mi casamiento, acá está la gente que quiero". "Una especie de familia disfuncional" dice Leo en referencia a sus amigos. De esta manera, la argentinidad aparece en ambos filmes ligada a rasgos culturales: el club de fútbol, la comida que se extraña (la bondiola de la costanera para Martín en Güelcom o el desayuno de la madre para Pedro en Lugares comunes); de los afectos (familia y amigos) que se necesitan; del sentimiento de resignación por un país que les resulta adverso para lograr sus objetivos. También se es argentino de acuerdo a la mirada de los otros. Por un lado, aparece el reproche de los que se quedaron a hacer patria mientras otros se fueron a salvarse solos. Y, por otro, la culpa y el enojo de los que fueron expulsados por las malas condiciones económicas y sociales de ese período histórico argentino.

Respecto a las marcas de la enunciación y los estereotipos, al analizar las representaciones del exiliado económico que proponen ambos filmes es posible observar que definen a un individuo ciertamente estereotipado: lo que, siguiendo a Umberto Eco (citado en Amossy y Herschberg, 2001), solo puede ser interpretado a partir de la inferencia de guiones preexistentes. Los que se fueron a España son jóvenes de clase media, cuya emigración responde a objetivos individuales relacionados con el bienestar económico. No tienen compromiso alguno con su país de origen, sino todo lo contrario, Argentina constituye el impedimento para su realización personal. Es un país expulsor, que solo es valorado por el afecto de amigos y familiares más cercanos, pero insuficiente para quedarse o volver a vivir allí.

Esa marca afectiva puede rastrearse en el uso de los deícticos, estos constituyen expresiones cuyo referente no puede determinarse sino en relación con los interlocutores. Son deícticos en la medida en que se interpretan con respecto a la localización de los participantes en el contexto enunciativo. Según Emile Benveniste (1974) son índices de ostensión, términos que sirven para designar el objeto al mismo tiempo que es pronunciado el término. En ambos filmes, los personajes usan, para hacer referencia a España, el deíctico allá, mientras que para nombrar a Argentina se utiliza el acá. Acá, como próximo al hablante; allá, en el campo de referencia de la tercera persona. La trayectoria del acá involucra una cercanía íntima que determina un mayor nivel de subjetividad. Hace referencia a una locación ocupada por el hablante, una marca que sujeta a los personajes a su tierra de nacimiento.

\section{Elementos estéticos y narrativos}

La verosimilitud en las historias contadas está dada por el planteamiento oportuno del espacio, el tiempo, los personajes y el uso de los elementos estéticos. Destacaremos algunos de los recursos del lenguaje cinematográfico elegidos por los directores para darle forma al exiliado económico en cada uno de los filmes. 
Como ya mencionamos, el punto de vista en ambos filmes es subjetivo/interno. El espectador conoce todos los hechos de la historia a través de la mirada del protagonista masculino. Tanto en on como en off sabemos lo que sienten y piensan ellos sobre los emigrados, es su mirada, su ideología del exilio económico (del hijo en Lugares comunes y de la novia en Güelcom).

En Lugares comunes se produce un quiebre del punto de vista cuando el narrador, Fernando, muere y esa voz es reemplazada por su compañera, quien terminará de cumplir los sueños truncos de su compañero - publicar su libro y hacer esencias de lavanda en Córdoba- en lugar de emigrar a España con su hijo. La mirada condenatoria de Lili sobre la migración de su hijo no cambia a lo largo de la trama ni difiere de la de Fernando.

Tanto Aristarain como Blanco utilizan un tiempo diegético lineal, es decir un tiempo cronológico, que transcurre entre la jubilación de Fernando y su muerte en Lugares Comunes y entre la partida de Ana y la partida de Leo en Güelcom.

La diferencia está en la estructura narrativa. El director de Güelcom explica la historia de amor de los protagonistas, primero, utilizando el racconto: la locación de la primera escena, es la misma playa catalana de la escena final, desde donde el protagonista cuenta la historia, y donde decide emigrar. Y luego recurre al flashback para narrar los cuatro años trascurridos entre la emigración de su novia y la suya.

Respecto a la puesta en cámara y en escena, los filmes de Adolfo Aristarain son conocidos por la sencillez de los elementos visuales y Lugares comunes no es una excepción. Prima la sobriedad y la prolijidad en los planos, con secuencias y escenas largas en las que la cámara está al servicio de los diálogos.

A través de planos medios y planos conjuntos, el espectador se acerca a los protagonistas, pero con una distancia que se asemeja al campo de imagen que nos proporciona una escena teatral. Recurre muy poco a los primeros planos, puntualmente cuando quiere la atención del espectador. Por ejemplo en el detalle de un manuscrito que nos cuenta mucho del protagonista. En este sentido, Bonitzer (2007) señala que "con el primer plano se rostrifican los objetos o las personas y sin primer plano, sin rostro, no hay suspenso, no hay terror" (pp. 21-22), en este caso no hay drama. Este recurso también se utiliza cuando los estudiantes escuchan con atención los consejos del ético profesor o para mostrar el dolor de Lili en el aeropuerto de Madrid en el momento de despedir a su hijo.

Aristarain no utiliza juegos ni movimientos abruptos. La cámara se mueve poco, trabaja con planos estáticos y planos generales para mostrar ese mundo que rodea a los personajes, que los hace pequeños, con poco poder de maniobra ante la realidad, como en el western. ${ }^{9}$ En la escena del bar que se analizó con anterioridad, donde se producen los dos diálogos identitarios más importantes del filme entre nuera y suegra y entre padre e hijo, la cámara parte de un plano general para mostrarnos la puesta en escena de un típico bar madrileño y, luego, busca dos conversaciones diferentes, pero con un mismo tema. En este caso prefiere no mostrar a las dos parejas en un plano entero, sino que participa al espectador de la tensión de esos diálogos y lo obliga a concentrarse en el discurso y la gestualidad de quien habla, a través del plano y contraplano. Este recurso genera, además de tensión dramática, empatía con los sentimientos de los personajes: frustración, traición, impotencia, desaliento. 
Yago Blanco, en cambio, recurre a los primeros planos a lo largo de toda la narración, nos acerca a los protagonistas y nos mezcla con ellos en las charlas de la pareja protagonista o las del grupo de amigos. Escasean los planos generales y abundan los primeros planos y planos medios. Siempre podemos ver las expresiones de las caras como si estuviéramos muy cerca de la escena. La cámara se mueve inteligentemente entre los personajes, incluso apela a los planos y contraplanos, y los elige en lugar de los planos conjuntos, para generar mayor tensión entre los personajes.

En Güelcom la puesta en cuadro se basa en la combinación y sucesión de planos cortos que aceleran el ritmo de la narración, le aportan dinamismo y agilidad. Yago Blanco utiliza estos recursos del lenguaje televisivo, dada su experiencia en ese oficio ${ }^{10}$. Aristarain, en cambio, construye la larga duración material y psicológica de los planos, dotando a Lugares comunes de un ritmo lento, aunque no aburrido.

Respecto a la puesta en escena es importante destacar la elección del aeropuerto como locación para narrar los encuentros entre los que se fueron y los que se quedaron. Se trata de una constante en ambos filmes. En Lugares comunes se narra la secuencia del reencuentro: primero, en el free shop Fernando compra un perfume para Lili, acción que remite a la clase media a la que pertenecen los viajeros. Un plano general del avión que traspasa las fronterasentre España y Argentina y, por último, el reencuentro familiar en el aeropuerto de Madrid.

En Güelcom, vemos a Ana llegando al Aeropuerto Internacional argentino donde tiene su primer choque de amor-odio con su país de origen al creer equivocadamente que le robaron el bolso. En la misma locación, el director elige contar otro arribo, muestra a los cinco amigos esperando a la pareja que falta, que viene a casarse a la Argentina.

El aeropuerto es el símbolo del reencuentro, en el primer caso con la Argentina, en el segundo con las amistades.

Respecto al uso de la luz y el color, cabe señalar que en Lugares comunes, a través de escenarios naturales, la cámara nos muestra los contrastes de una época. Por un lado, la Madrid luminosa y esplendorosa de principios de los 2000, y la belleza árida y la paz otoñal de Traslasierra en Córdoba. Por otro, la atmósfera de desesperación de una Buenos Aires en plena crisis económica que el director construye en el montaje, alternando el living oscuro y opaco donde está sentado Fernando con la realidad mediada por una pantalla de televisor que desprende imágenes frías, azuladas, que muestran las protestas de un puñado de jóvenes entre la humareda y la policía montada.

La luz enfatiza los volúmenes de los objetos y personajes acentuando, por su condición especial, las distancias y la percepción de realidad: da la sensación de ser natural en todo el filme. Tenue, con contrastes de luces y sombras en los interiores del departamento antiguo y hogar cálido en el que han vivido toda la vida los protagonistas, y plena en los exteriores que recorren los personajes. Como excepción podemos nombrar la escena del hospital, donde la luz blanca dota de simbolismo la muerte de Fernando.

Pero el color es otoñal. Juega con una tonalidad que representa la última etapa de vida del protagonista. El uso pictórico del color del paisaje campestre donde Fernando muere, cita a los óleos cordobeses de Fader. ${ }^{11}$ 
En Güelcom la puesta de luz es vivaz pero plana, remite al lenguaje televisivo. Siguiendo esa estética publicitaria -con mucho maquillaje, peinados perfectos y actores vestidos como modelos auspiciados-, se utiliza la luz para remarcar los rostros como se hace con los productos o servicios en venta. Cálidos, iluminados y saturados, aquí los colores son los del verano, de los días soleados que se ven en los exteriores de Buenos Aires y de Barcelona, o por los ventanales de los interiores de cada una de las locaciones elegidas. El fondo siempre iluminado y claro intensifica esos colores y da una atmósfera de alegría, de final feliz.

Respecto a la banda sonora, en Lugares comunes, acompaña el tono emotivo del filme y le aporta buen ritmo, pero tiene un rol secundario, ya que la prioridad está en los diálogos y los monólogos del protagonista. Cabe destacar la elección de dos boleros: el primero Amor de mis amores de María Teresa Lara, acompaña los créditos y nos introduce en la historia de amor; el segundo, El soldado, interpretado por la cubana María Teresa Vera, cierra la historia.

"Adiós, adiós, lucero de mis noches, dijo el soldado, al pie de la ventana, me voy, me voy, pero no llores, ángel mío, que volveré mañana”.

Las estrofas aluden a la despedida de quien sabe que morirá, como es el caso de Fernando, que se despide del amor de su vida, pero también es una alegoría a las despedidas que atraviesan las subtramas del filme. De padres e hijo a causa del exilio económico, de amigos a causa del exilio interno. Y el que se despide es un soldado, que murió dando todo en la batalla, como Fernando, que no claudica.

Pero el adiós es un hasta luego, porque siempre está la esperanza del retorno cuando quedan seres queridos por los que volver.

En Güelcom, en cambio, la banda sonora es prácticamente un protagonista más; tal como dice Michel Chion (1993), la música aporta un "valor añadido, designando valor expresivo e informativo a la imagen dada" (p.16).

La música en este filme narra, ambienta, acompaña y da ritmo. Siguiendo a Chion 1993), podemos clasificarla como música empática, ya que nos facilita transitar por los sentimientos que atraviesan los distintos personajes. "La música expresa directamente su participación en la escena, adaptando el ritmo, el tono y el fraseo, en función de códigos culturales de la tristeza, de la alegría, de la emoción y del movimiento" (Chion, 1993, p.19). En la mayoría de los casos es diegética, es decir que no solo arma la escena para el espectador, sino

que también está siendo escuchada por los protagonistas. Ejemplo claro es la siguiente escena con el paciente del psicólogo Leo, un músico tapado que gracias a la terapia y a la escucha de sus canciones en la sesión, se transforma en profesional y su guitarra será el acompañamiento de otras escenas. También el violinista que participa en el pedido de casamiento de Oriol a Ana. O durante el casamiento de Martín y Julieta, donde la interrupción de la banda en vivo propicia el desenlace del filme. 
El tema original Reloj de avena de Edu Schmidt -exintegrante del exitoso grupo de rock Árbol- se escucha durante toda la trama en versión instrumental y revela la letra al final, mientras vemos a los protagonistas caminando de la mano en la playa de Barcelona:

"Quiero vivir en cámara lenta, que el mundo tarde en dar la vuelta

(...)

Sé que todo va a llegar en algún momento en algún lugar”.

En este punto, sostenemos que la banda sonora define dos estilos diferentes, pero también dos públicos diferentes. Aristarain le habla a su generación, a los que se enamoraron con los boleros, que son los mismos que en los años 2000 habían vivido varias dictaduras, que se habían ilusionado y decepcionado de la democracia. Por su parte, Yago Blanco se dirige a un público treintañero, que conoce a las estrellas de televisión a las que eligió para su ópera prima, a una generación que escucha pop desde su nacimiento, que se supone desencantada de lo colectivo, que apuesta por cumplir sus sueños donde sea posible.

Los elementos gráficos también difieren en los filmes y hablan de destinatarios diversos: en Lugares comunes solo se utilizan para los créditos, con una tipografía que suele ser utilizada en el género literario y en la escritura académica, como la que posiblemente usase el protagonista. En Güelcom el director juega con la animación de las placas gráficas en distintos idiomas y colores para evidenciar los puntos de giro de la narración y el desenlace con el último benvinguts, bienvenidos en catalán, dando cuenta del destino final de los protagonistas.

\section{La historia en la historia: crisis del 2001}

Ambos filmes no solo dan cuenta de la vida de aquellos que emigraron, sino que producen determinada versión, explicación de la historia reciente.

$\mathrm{Al}$ respecto es posible señalara que Lugares comunes dialoga con su época, y representa un mundo en el que los problemas económicos afectan a cada uno de los personajes. El contexto histórico de la Argentina durante los meses de diciembre del 2001 o enero del 2002 se muestra a través de una pantalla de televisor que está en el living del departamento, el mismo que los protagonistas han puesto en venta para poder subsistir. En el sillón, Fernando, desempleado y sin posibilidades de conseguir nuevo trabajo, mira las imágenes de archivo de los argentinos de clase media que corrían a las ventanillas a reclamar por su ahorros. El dinero está acorralado en los bancos, los ciudadanos están acorralados por la policía. Se ven colas de personas que buscan trabajo y la imposibilidad de acceder a un crédito. Mientras tanto, frente a Fernando y su televisor, desfilan la asesora inmobiliaria y posibles compradores, que él parece no ver. Como si las imágenes de ese aparato electrónico lo hipnotizaran y no pudiera creer lo que han hecho con su país aquellos que el pueblo eligió con los mismos preceptos democráticos que él defiende y predica. 
Sabemos de esa crisis económica desde una de las primeras escenas, cuando el rector del instituto donde trabaja Fernando lo jubila de forma anticipada, porque no hay presupuesto educativo. El rector es una metáfora de los históricos saqueadores del Estado argentino contra los cuales luchó siempre el protagonista, pero también simboliza al gobierno neoliberal de ese preciso momento histórico.

Por su parte, Pedro, el hijo, recibe a sus padres en Madrid del 2001, previo a la debacle argentina. España ha ingresado a la Unión Europea. Esta situación se condensa a modo de metáfora con la elección de la postal de la Puerta de Europa. La imagen da cuenta de dos rascacielos inclinados donde funcionan un banco y una inmobiliaria, con esta elección la película da cuenta del contraste entre la situación crítica que vivía la Argentina y la de esplendor en que se encontraba España.

-Ni se te ocurra volver, está todo peor, aquí la miseria no se nota —le dice Fernando a su hijo en Madrid. Este mensaje tiene una doble carga de sentido, porque lo enuncia un exiliado político retornado, padre de un exiliado económico. Dos momentos de la historia de la Argentina diferentes, dos generaciones de una familia, un mismo problema: la incapacidad de los gobiernos para generar una política y una economía estables, y la consecuente emigración. Por lo señalado, es posible pensar Lugares comunes desde el planteo de Caparrós Lera (2004) cuando sostiene que "sin una voluntad directa de hacer historia, posee contenido social y, con el tiempo, pueden convertirse en testimonio importante de la Historia, o de las mentalidades de cierta sociedad en determinada época” (p. 24).

Desde otro género, Güelcom se sitúa en el mismo momento histórico que Lugares comunes, aunque en este filme no hay elementos específicos que remitan a los hechos históricos que marcaron el contexto. Los personajes que emigran no evidencian problemas económicos, sino de realización personal. También presenta ese país que expulsa a los jóvenes de clase media de las ciudades más prósperas hacia el país de los abuelos, en el caso de Pedro, y de las oportunidades y la tranquilidad, en el caso de Ana, Martín y Julieta. En esta comedia no prevalece la desesperanza como en el drama de Aristarain. Aquí, los chistes de los amigos y de las ironías del protagonista, se muestran atravesados por las huellas del pasado reciente, del dolor de los que se fueron y de los que se quedaron en la Argentina de principios de los 2000. No obstante presenta la falta, la ausencia de los jóvenes de clase media que han sido expulsados del país. Imposible no leerla desde las palabras de Pierre Sorlin (1985) cuando expresa que una "película está íntimamente penetrada por las preocupaciones, las tendencias y las aspiraciones de la época” (p. 43).

Por último, los personajes emigrados encontrarán trabajo en España, aunque vale la pena marcar una diferencia. En Lugares comunes Pedro ejerce como profesional de la informática, mientras que en Güelcom Ana, Martín y Julieta tendrán que conformarse con trabajar de camareros. En el presente construido por la enunciación fílmica no revela si Leo ejercerá o no su profesión en España, pero podemos inferir que esa elección responde a otro lugar común: Argentina como fábrica y exportadora de psicólogos. 


\section{El contexto}

Lo importante, según lo define Pierre Sorlin (1985), es la influencia en los filmes del mundo de las mentalidades, de la ideología de cada época y cultura. Su estudio sobre la relación entre el cine y la historia lo efectúa como parte de un juego de espejos, en que ambos se ven reflejados e influenciados a través del hilo conductor común, que es la sociedad que los produce.

En este caso, los filmes presentan dos contextos de producción muy diferentes. Durante los peores años de la crisis, 2001 y 2002, se estrenaron solo 47 filmes. Mientras que en 2011, ese número creció a 117 (INCAA). Esta diferencia se traduce en los tonos con que ambos directores cuentan la crisis del modelo neoliberal y la emigración.

Los números de emigrantes en ese lapso también marcan una diferencia. Entre 2001 y 2003 emigraron los argentinos hacia Europa y en 2011 el sentido de los migrantes era inverso. No solo retornaron argentinos, sino que también hubo un flujo de inmigrantes españoles jóvenes (Carbajal, 24 de febrero de 2014). En 2011 algo más de 55 mil españoles salieron del país, cifras que no se registraban, al menos en las estadísticas oficiales, desde 1975 (Romero-Valiente e Hidalgo-Capitán, 2014).

Aristarain decía sobre Lugares comunes que "no se trata de una película de denuncia político-social, sino de una profunda historia de amor" (El País, 11 de julio de 2002). Sin embargo, la situación económica, política y social que vivía la Argentina en el momento de rodaje de este filme coincide con lo que acontece en el tiempo de la narración, el amor de una pareja que vive en un contexto adverso, bajo condiciones estructurales de un Estado hostil que los obliga a vivir reinventándose y que les ha expulsado al único hijo que tienen. Además, se estrenó en las pantallas el 12 de septiembre de 2002 cuando Argentina vivía el éxodo más significativo de ciudadanos de toda su historia. Como señaló Monterde (2001):

Como todo producto cultural, una red de discursos elaborada de una forma mediatizada por las ideologías y las condiciones estructurales de un momento dado, el film no aparece como un momento neutro en la sociedad que lo produce, sino que adquiere un componente de intervención sobre la sociedad (Monterde, 2001, p. 41).

A tales efectos, vale la pena contar como dato de color el paralelo que viven Fernando, jubilado al que nadie le da trabajo, que en lugar de gozar de los ahorros de su vida tiene que pensar estrategias para sobrevivir; con el actor que encarna a Fernando: Federico Luppi. A días del estreno, decía en el diario La Nación (16 de septiembre de 2002): "Pensé que a la edad que yo tengo, podría asegurarme cierto bienestar. Laburaba en España y la guita la ponía en la Argentina. Pero me sacaron cinco o seis años de laburo". En ese momento Luppi era un emigrado en España a causa del corralito. A diferencia del actor, su personaje, Fernando, se quedó en Argentina hasta el final de sus días.

En una nota del Suplemento "Radar" de Página 12 Aristarain aclaraba: "Para no tener que andar hipotecando la casa tendría que hacer una película por año. Y no la hago ni en 
pedo [sic]" (Pérez, 8 de septiembre de 2002). Esta confesión también nos habla de cómo las condiciones de producción están íntimamente asociadas con el producto cultural que aquí se analiza.

Lugares comunes no es una foto instantánea de la Argentina del 2001/2002, es necesario pensarla como construcción, en el sentido dado por Monterde (1986) un "simulacro con mayor o menor apariencia de verdad que si bien es conocida como tal, es capaz de mantenernos - por su lógica interna llamada verosimilitud- en una lógica semejante a la que tendríamos ante circunstancias de nuestra propia realidad" (p. 74).

Lugares comunes cumple con una funcionalidad histórica y tal vez Aristarain, en su descripción del filme, estaría de acuerdo con la afirmación del director francés Jean-Luc Godard: "No hay que hacer filmes políticos, sino hacer cine políticamente" (Chiesi, 2003).

En cuanto a la producción de Güelcom, Yago Blanco contó en una entrevista:

Empecé a imaginarla cuando muchos amigos y seres queridos se iban a vivir afuera enojados con el país y dejando entrever que los que nos quedamos éramos medio boludos [sic]. Se iban a Europa a trabajar de cosas que acá no se les hubiese cruzado por la cabeza. Eso hizo que me enojara mucho esa actitud. Así que las primeras versiones del guion eran más ácidas y menos amigables para con los que se iban. Con el tiempo, ese enojo se fue apaciguando y fui entendiendo que era una decisión (Haciendo Cine, 2011).

Blanco realizó su ópera prima ocho años después de empezar a escribir el guion. Esto hizo que el tema central quedase desfasado de su contexto de producción y por eso Güelcom habla más de los regresos que de las partidas y lo hace desde la ironía, en la comedia, a diferencia del drama, quizás único género posible desde el cual contar en el contexto de 2002. Es importante señalar que en agosto del 2011, cuando se estrenó Güelcom, la Argentina había mejorado los índices económicos, y esa estabilidad se ve en los personajes del filme que se quedaron en Argentina. Ellos visten a la moda, tienen trabajo, realizan actividades deportivas y sociales, no expresan problemas económicos de ningún tipo. En ese momento histórico, los que emigraban eran los jóvenes españoles, y los argentinos, como otros migrantes latinoamericanos, retornaban a sus países de origen. ${ }^{12}$

Si bien la explicación más extendida asocia el retorno de los argentinos a las consecuencias de la crisis internacional en el mercado de trabajo español, los estudios (Actis y Esteban, 2008; Cerruti y Maguid, 2016; Schmidt, 2014) concluyen que la decisión de retorno es compleja, porque viene acompañada de otras razones, tanto de carácter afectivo-emocional como de políticas de retorno de sus países de origen.

A partir del 2008 el Estado argentino comenzó a desarrollar políticas públicas para incentivar el retorno de argentinos en el exterior. En el Censo de Hogares del 2010 se incluyeron preguntas sobre familiares que viviesen en el exterior como estrategia para transformar estimaciones en datos certeros.

En el año 2013 el número de inmigrantes bajó por primera vez de forma significativa con casi 200.000 personas empadronadas menos (5.546.238) que en el año anterior. Según la 
Estadística de Variaciones Residenciales, elaborada por el Instituto Nacional de Estadística de España (INE), en enero de ese año residían en España 270.419 argentinos, un 3,6\% menos que un año antes. ${ }^{13}$

A pesar de ese contexto, Yago Blanco decidió que en el final de su filme los protagonistas tuvieran un proceso migratorio inverso. Ana retornó a España y se llevó a Leo. La clase media representada en el filme que cuenta con un capital económico, social o cultural, a la cual pertenecen los personajes de Güelcom, sigue pensando en Europa como una variable de futuro.

Vale la pena detenerse en la caracterización que hacen Anguita y Minujín (s. f.) de la clase media como aquella "que cuenta con cierto capital, el cual puede ser tanto económico, como social y/o cultural" (p. 4). Si bien se trata de un sector heterogéneo de la población argentina, los autores sostienen que a partir del plan económico de la última dictadura cívico-militar este sector comenzó un proceso de empobrecimiento que se acrecentó con la profundización del modelo neoliberal de los años noventa y llegó al quiebre durante la crisis del 2001.

Los autores postulan que ese fuerte empobrecimiento abarcó no solo lo material, sino también lo social y lo ético, en tanto introdujo un estilo de pensamiento de "supervivencia de los más aptos mediante las vías del mercado" (p. 16). Tal vez, este imaginario social que ha permeado las generaciones poscrisis justifica la elección de Yago Blanco: Ana, Julieta y Martín regresan a España acompañados del protagonista que se ha pasado toda la trama enunciando críticas sobre aquellos que se fueron.

\section{A modo de cierre}

A lo largo del análisis de los filmes hemos podido ver condensadas las migraciones entre España y Argentina en doble dirección y en diferentes etapas de nuestra historia. Tanto Güelcom como Lugares comunes son presentadas como historias de amor romántico, sin embargo, en ambas películas prevalece como tema estructural la representación de una Argentina que expulsa a sus jóvenes de clase media.

En los dos filmes la emigración aparece como una acción voluntaria e individual. A diferencia de la representación del exiliado de los años setenta que emigró por razones políticas que implicaban la vida o la muerte; el exiliado económico no cree en las opciones que pueda brindarle Argentina, o estas no satisfacen sus necesidades de realización personal o económica.

Tanto Aristarian como Blanco representan en sus filmes a jóvenes estereotipados, de clase media de la Ciudad de Buenos Aires, que se van al exterior en búsqueda de algo mejor de lo que tienen en su país, lo encuentren o no. Las películas comparten y reproducen el imaginario social: Europa como el centro del mundo y referente cultural innato. Mirada que los directores refuerzan con la elección del casting. Todos los personajes responden al patrón de belleza europea y el tópico fundacional de la argentinidad relacionada con el crisol de razas. 
Es necesario señalar que si bien la dramaturgia se centra en migrantes, el proceso migratorio no aparece en ninguno de los dos filmes. Los emigrados ya están viviendo en España, no sabemos nada sobre su partida ni sobre su llegada. Lo que está en juego para ambos directores es si vuelven a la Argentina o no.

La argentinidad, en ambas películas, está ligada a lo cultural (costumbres, uso del lenguaje) y al afecto de los más cercanos (somos amigueros, familieros). Por su parte, las referencias a la Argentina como país son negativas. Es un país culpable, que no propicia condiciones de vida. Una Argentina en crisis constante que condena a sus ciudadanos a padecerlas en primera persona.

Por el contrario, en sendos filmes, la españolidad aparece a nivel narrativo ligada a tener un documento que la legitime. España es representada como el paraíso donde poder concretar los sueños. Esto genera una tensión con el desarrollo de los personajes que han tenido que resignarse y hacer trabajos que no se corresponden con sus expectativas previas al momento de emprender el proceso migratorio. De todas maneras, los exiliados económicos de los filmes no se autoperciben inmigrantes.

Los personajes que se quedaron, en ambas películas, tienen la misma contradicción: intentan desmitificar el afuera como salvación, pero terminan dándole la razón a los que han marchado para salvarse.

Raymond Williams (2012) entiende que solo es posible comprender una cultura dominante si entendemos el proceso social real del cual depende, es decir, el proceso de incorporación. En ambos filmes podemos apreciar esa capacidad de agencia de transmisión de la cultura dominante.

La frase de Fernando "el futuro existe, se compra con dinero" resume el pesimismo que ambos directores, desde distintos géneros, distintas trayectorias e incluso distintos puntos de vista, imprimen sobre el tema que nos interesa en este trabajo. Los emigrantes son víctimas del sistema neoliberal que ha gobernado la Argentina durante décadas, y la implementación de un modelo nacional y popular que revierta el éxodo y propicie el retorno de los exiliados económicos no termina de convencer a aquellos que tienen la posibilidad de permanecer en España, a pesar de ser bienvenidos, como indica Blanco en distintos idiomas a lo largo de todo el filme.

\section{Bibliografía}

Anguita, E. y Minujín, A. (s. f.). Capítulo 1. El proceso de empobrecimiento. El largo camino hasta el hoy. UNTREF virtual. Recuperado de http://materiales.untrefvirtual. edu.ar/documentos_extras/01082_Cuestiones_de_soc_eco_y_pol/Unidad3/MinujinAnguita_El-Proceso-de-Empobrecimiento.pdf

Actis, W. y Esteban. F. (2008). Argentinos en España: inmigrantes a pesar de todo. Migraciones (23). Madrid: Universidad Pontificia de Comillas.

Agamben, G. (1996). Política del exilio. Archipiélagos. Cuadernos de crítica de la cultura. Barcelona, No 26-27. 
Amossy, R. y Herschberg A. (2001). Estereotipos y clichés. Buenos Aires: Eudeba. Augé, M. (2000). Los no lugares. Espacios del anonimato. Barcelona: Gedisa. Benveniste, E. (1974). Problemas de lingüística general, t. II. México: Siglo XXI.

Bonitzer, P. (2007). El campo ciego. Ensayos sobre el realismo en el cine. Buenos Aires: Biblioteca Kilómetro 111.

Bordwell, D. (1996). La narración en el cine de ficción. Barcelona: Paidós.

Caparrós Lera, J. M. (2004). 100 películas sobre la historia contemporánea. Madrid: Alianza. Cerruti, M. S. y Maguid, A. (2016). Crisis económica en España y el retorno de inmigrantes sudamericanos. Migraciones Internacionales, vol. 8, nro. 30. Recuperado de https:// migracionesinternacionales.colef.mx/index.php/migracionesinternacionales/article/ view/618/160

Chiesi, R. (2003). Jean-Luc Godard. Gremese Editore.

Chion, M. (1993). La audiovisión. Introducción a un análisis conjunto de la imagen y el sonido. España: Paidós Ibérica.

Esteban, F. O. (2003). Dinámica migratoria argentina: inmigración y exilios. América Latina hoy, 34: 15-34.

Ferro, M. (1991). Perspectivas en torno a las relaciones Historia-Cine. Film-Historia. (Vol. I, No.1, pp 3-12). Recuperado de http://www.publicacions.ub.es/bibliotecadigital/cinema/ filmhistoria/Art.M.Ferro.pdf

Fischer, G.N. (1996). Les concepts foundamentaux de la psychologie sociale. Dunod Fiske, S.T. \& Taylor, S. (1991). Social cognition. New York: Mc-Graw-Hill.

Grinberg, L. y Grinberg, R. (1984). Psicoanálisis de la migración y del exilio. Madrid: Alianza.

Hall, S. (2003). Introducción: ¿quién necesita “identidad”?. En Hall, S. y Du Gay, P. (comps). Cuestiones de identidad cultural. Buenos Aires: Amorrortu Editores.

Minujín, A. y Anguita, E. (s. f.). Capítulo 1. El proceso de empobrecimiento. El largo camino hasta el hoy. UNTREF virtual. Recuperado de http://materiales.untrefvirtual. edu.ar/documentos_extras/01082_Cuestiones_de_soc_eco_y_pol/Unidad3/MinujinAnguita_El-Proceso-de-Empobrecimiento.pdf

Monterde, J. E., Masoliver, M. S. y Solá, A. (2001). La representación cinematográfica de la historia. Madrid: Akal, Madrid.

Monterde (1986). Cine, historia y enseñanza. Barcelona: Laia.

Norá, P. (1998). La aventura de Les lieux de Mémoire. Ayer. Revista de la Asociación de Historia Contemporánea, nro. 32.

Rosenstone, R. (2014). La historia en el cine. El cine sobre la historia. Madrid: Rialp.

Rosenstone, R. (1997). El pasado en imágenes. El desafío del cine a nuestra idea de la historia. Barcelona: Ariel.

Schmidt, H. (2014). Crónicas del retorno. Motivaciones y estrategias del colectivo argentino en España. Observatorio de Inmigración - Centro de Estudios y Datos. Dirección General de Inmigración. Comunidad de Madrid: Consejería de Asuntos Sociales.

Sorlin, P. (1985). Sociología del cine. La apertura para la historia del mañana, México: FCE.

Todorov, T. (1995). Los abusos de la memoria. París: Arléa.

Williams, R. (2012). Cultura y materialismo. Buenos Aires: La Marca Editora. 


\section{Fuentes}

Carbajal, M. (24 de febrero de 2014). El éxodo que cambió de sentido. Página 12. Recuperado de https://www.pagina12.com.ar/diario/elpais/1-240497-2014-02-24.html

DNM-INDEC (2004). Dirección Nacional de Migraciones. Instituto Nacional de Estadísticas y Censos. Buenos Aires. Recuperado de https://www.indec.gob.ar/indec/web/ Nivel4-Tema-2-18-78

El País (11 de julio del 2002). Aristarain vuelve a rodar con Luppi. Recuperado de https:// elpais.com/diario/2002/07/12/cine/1026424810_850215.html

Instituto Nacional de Estadística de España [sitio web]. https://www.ine.es/

Intxausti, A. (13 de noviembre de 2003). Cultura premia la rigurosa carrera de Mercedes Sampietro. El País. Recuperado de https://elpais.com/diario/2003/11/13/espectaculos/1068678001_850215.html

Kairuz, M. (15 de junio de 2014). Detrás de las paredes. Suplemento “Radar”. Página 12. Recuperado de https:/www.pagina12.com.ar/diario/suplementos/radar/9-9800-2014-06-15. html

La Nación (18 de marzo de 2007). Provincia 25, el distrito más allá de la frontera. Recuperado de https://www.lanacion.com.ar/politica/provincia-25-el-distrito-mas-alla-de-lafrontera-nid892399/

La Nación (16 de septiembre de 2002). Federico Luppi habla sobre la película de Adolfo Aristarain, recién estrenada. "Cada vez tengo menos cosas" [entrevista]. Recuperado de https://www.lanacion.com.ar/espectaculos/cine/cada-vez-tengo-menos-cosasnid431922/

López Letón, S. (24 de octubre de 2015). La burbuja que embriagó a España. El País. Recuperado de https://elpais.com/economia/2015/10/20/actualidad/1445359564_057964.html

Pérez, M. (8 de septiembre de 2002). Ningún lugar en el mundo. Suplemento Radar. Página 12. Recuperado de https://www.pagina12.com.ar/diario/suplementos/radar/9-365-2002-09-08.html

Portal de Inmigración. Datos de retorno voluntario. España. http://extranjeros.inclusion. gob.es/es/Retorno_voluntario/datos/index.html

Randstad (18 de septiembre de 2019). El 84\% de los argentinos consideraría emigrar para mejorar su carrera profesional. Recuperado de https://www.randstad.com.ar/quienessomos/sala-de-prensa/sala-de-prensa/el-84-de-los-argentinos-consideraria-emigrarpara-mejorar-su-carrera-profesional/

\section{Fichas de los filmes analizados}

Lugares comunes (Argentina/España, 2002)

Dirección: Adolfo Aristarain.

Producción: Adolfo Aristarain, Gerardo Herrero (Tornasol Films) y Shazam SA. 
Guion: Adolfo Aristarain y Kathy Saavedra, sobre la novela El renacimiento, de Lorenzo F. Aristarain.

Dirección de arte: Abel Facello

Sonido: Goldstein \& Steinberg.

Montaje: Fernando Pardo

\section{Intérpretes}

Federico Luppi: Fernando

Mercedes Sampietro: Liliana

Arturo Puig: Carlos

Carlos Santamaría: Pedro

Valentina Bassi: Natacha

María Fiorentino: Tutti Tudela

Claudio Rissi (Demedio)

Director de fotografía: Porfirio Enríquez

\section{Premios}

Goya a la mejor actriz para Mercedes Sampietro y mejor guion adaptado para Adolfo Aristarain y Kathy Saavedra.

Medallas del Círculo de Escritores Cinematográficos de 2002, categoría mejor actriz para Mercedes Sampietro.

Festival Internacional de Cine de Donostia-San Sebastián-Concha de Plata a la mejor actriz para Mercedes Sampietro, y premio del jurado al mejor guion-Adolfo Aristarain y Kathy Saavedra.

Fotogramas de Plata a la mejor actriz para Mercedes Sampietro.

Güelcom (Argentina/España, 2011)

Director: Yago Blanco

Guion: Diego Núñez sobre una idea de Yago Blanco

Música: Eduardo Schmidt

Director de Fotografía: Iván Gierasinchuk

\section{Intérpretes}

Mariano Martínez: Leo

Eugenia Tobal: Ana

Peto Menahem: Javier

Maju Lozano: Andy

Eugenia Guerty: Sol

Gonzalo Suárez: Marto

Ana Yovino - Julieta

Chema Tena: Oriol 
Gustavo Garzón: Dr. Lorenzo

Agustina Cordova: Mirna

Nicolás Condito: Rollinga

\section{Notas:}

1. Son: Herencia (Paula Hernández, 2001); Lugares comunes (Adolfo Aristarain, 2002); El hijo de la novia (Juan José Campanella, 2002); Un día de suerte (Sandra Gugliotta, 2002); Luna de Avellaneda (de Juan José Campanella, 2003); Bar El chino (Daniel Burak, 2004); El abrazo partido (Daniel Burman, 2004); Como mariposas en la luz (Diego Yaker, 2004); Hermanas (Julia Solomonoff, 2005); La vida aquí (Jesús Font, 2003); Abrígate (Ramón Costafreda, 2006); El método (Marcelo Piñeyro, 2006); Pagafantas (Borja Cobeaga, 2009); Güelcom (Yago Blanco, 2011); Nadie nos mira (Julia Solomonoff, 2017).

2. El término es un neologismo introducido por el antropólogo Marc Augé (2000) en su obra Los no lugares, espacios del anonimato: una antropología de la sobremodernidad. La percepción de un espacio como no-lugar es subjetiva: cada persona con su subjetividad puede ver un sitio dado como un no-lugar o como una encrucijada de relaciones humanas. 3. Según el informe Randstad Workmonitor de la consultora global Randstad, correspondiente al tercer trimestre del 2019, el 84 \% de los argentinos que trabaja está dispuesto a emigrar para mejorar su vida. La mayoría de las consultas fueron por España, seguida por Estados Unidos y Australia (Randstad, 18 de septiembre de 2019).

4. Mercedes Sampietro fue galardonada con el Premio Nacional de Cinematografía 2003 por su interpretación en Lugares comunes (Intxausti, 13 de noviembre de 2003).

5. El protagonista evalúa la migración argentina a través de frases estereotipadas, a las que engloba en la expresión las diez frases más usadas por los argentinos que se van de la Argentina: "Este país es una mierda [sic]", "Me fui porque acá no podía desarrollarme en lo mío", "Me voy para lograr mi independencia", "Fue una decisión muy meditada", "Allá hay mejores horizontes profesionales", "Me voy a probar suerte", "Allá hay otro nivel cultural", "Allá hay más oportunidades", "Allá se vive más relajado", "Me fui a probar suerte".

6. En el año 2000 el sector de la vivienda comienza a crecer desaforadamente. "Cada año se iniciaban una media de 600.000 casas, llegando al récord de 762.540 en 2006" (López Letón, 24 de octubre de 2015).

7. “¿Cómo se puede vivir sabiendo esto, siendo tan lúcido, tan consciente de la precariedad del hombre? ¿Cómo se puede convivir con el Absurdo a una edad en la que es difícil protegerse con el cinismo? La lucidez no viene sola, viene acompañada por una fuerza vital, por una especie de motor que transforma esa conciencia, esa angustia, en energía. Esa energía, ese impulso, genera a su vez alegría, una sensación de orgullo por saberse capaz de vivir sin mentirse aunque duela" (Fragmento del ensayo "Los lúcidos", escrito por Adolfo Aristarain, incluido en el libro Cine y oficios, que se publicó por la editorial española Ocho y Medio en el 2004 y que formó parte del filme). 
8. Adolfo Aristarain dirigió Un lugar en el mundo, película que se estrenó en 1992. El filme, situado en los años noventa del neoliberalismo, trata sobre recuperar la ética, la solidaridad, la justicia social y la fidelidad a la ideología. Lugares comunes podría ser su continuidad, desde el actor protagonista, Federico Luppi, hasta la temáticas del exilio y el retorno. La diferencia se da en el mensaje final, en Lugares comunes no hay segunda oportunidad, sino desesperanza.

9. En la filmografía de Aristarain hay múltiples referencias a sus películas preferidas: westerns, thriller y el cine negro; y a escritores que hacen de los diálogos uno de los distintivos de su prosa. Esto ha influido en sus propios filmes. En este caso, el espíritu de frontera para construir un nuevo mundo como en las películas del oeste y el anhelo de ser libre en el cine negro o el destino trágico de sus protagonistas.

10. Yago Blanco es diseñador de imagen y sonido, ha dirigido publicidades, videoclips y ha trabajado como realizador en el canal de TV Telefe durante 14 años.

11. Fernando Fader, pintor argentino, nacido en Burdeos, Francia, principal seguidor del impresionismo alemán en Argentina.

12. Por retorno se entienden al menos dos situaciones: por un lado, los que retornan definitivamente, al ver frustradas las expectativas con las que emprendieron el proyecto migratorio; por otro, los que vuelven para reemigrar en mejores condiciones. Pero en todos los casos, retornar es volver a emigrar, en tanto implica para quienes lo experimentan un cambio vital significativo (Grinberg y Grinberg, 1984).

13. La Estadística de Variaciones Residenciales (EVR) es elaborada por el INE a partir de la información relativa a las altas y bajas en los padrones municipales de habitantes motivadas por cambios de residencia. Así se obtienen los saldos por variación residencial anuales, tanto los interiores -entre los diferentes municipios de España- como los exteriores -entre municipios de España y el extranjero-.

\footnotetext{
Abstract: The aim of this article is to analyze the representation of Argentine economic exiles in fictional films produced in Argentina between 2001 and 2011.

We will focus on tracking the strategies and resources used by the films to build the characters, taking as a hypothesis that these constructions reinforce the prejudices that come from the real world. Secondly, we propose to inquire about the historical context represented: Argentina's 2001 economic, political and social crisis.

The corpus of films is made up of: Common ground (Aristarain, 2002) and Güelcom (Blanco, 2011), fictional films produced in different important historical moments to address the emigration to Spain, and the return to Argentina. The approach that we proposed in the article understands the cinema as an artifact of memory, which allows us to look at the past that we choose to remember, but also what we want to forget.
} 
Keywords: economic exile - Argentinian emigrant - identity - crisis of 2001.

Resumo: O objetivo deste artigo é analisar a representação dos exilados econômicos argentinos em filmes de ficção produzidos na Argentina entre 2001 e 2011.

Vamos nos concentrar em rastrear as estratégias e os recursos usados pelos filmes para construir personagens, partindo do pressuposto de que essas construções reforçam preconceitos que vêm do mundo real. Em segundo lugar, nos propomos a indagar o contexto histórico representado: a crise econômica, política e social argentina de 2001.

O corpus de filmes é constituído por: Lugares comuns (Aristarain, 2002) e Güelcom (Blanco, 2011), ficções produzidas em diferentes momentos históricos relevantes para abordar a emigração para a Espanha e o retorno à Argentina. A proposta de abordagem entende o cinema como um artefato de memória, que nos permite olhar o passado que escolhemos lembrar, mas também o que queremos esquecer.

Palavras chave: exílio econômico - emigrante argentino - identidade - crise de 2001.

[Las traducciones de los abstracts fueron supervisadas por el autor de cada artículo] 